\section{TUMOURS OF THE ORBIT.}

\section{To the Editor of THE LANCET.}

Str,-Allow me to make a few remarks on the discussion at the Royal Medical and Chirurgical Society, which occurred on the occasion of the reading of Mr. W. Rivington's paper "On a Case of Pulsating Tumour of the Left Orbit, consequent upon a fracture of the bones of the skull," as reported in the current number of your journal. I shall restrict myself to that part of the discussion which relates to orbital tumours, the diagnosis of which is notoriously difficult. Mr. Heath questioned the propriety of resting a diagnosis of aneurismal disease too exclusively on the bruit, as felt by the patient and heard on auscultation. Enough material has been gathered and recorded during the last dozen years, from the examination of patients and from post-mortem inspections, to assure us that perceptible pulsation in an orbital tumour, ascertained directly or through the medium of the eyeball, cannot be relied on as diagnostic of orbital aneurism.

Then followed Sir J. Paget's remarks in illustration of the cause of orbital pulsation, as might probably be gathered from the conditions of pulsation of tumours situated in bony cavities. He showed that a tumour of any sort in a bony canal may receive a considerable pulsation from bloodvessels of small size in the cavity or in its walls, \&c. \&c., and farther that the fat in the orbit, which is fluid at the temperature of the body, on which the eyeball floats freely, is a favourable medium for transmitting pulsations to the eyeball, when there is some disturbance in the orbital system of circulation. I wish, however, to draw attention to another fluid medium which operates in the same direction; I mean the accumulation of serum in the tunica vaginalis oculi-the capsule which surrounds the optic nerve and the eyeball. I am the more desirous of writing about it as the tunic is not generally described by anatomists, and the extensive bearing which it has on orbital pathology is scarcely recognised by surgeons.

In all cases of protrusion of the eyeball attended with orbital inflammation or orbital infiltration, the ocular tunic becomes more or less distended by serum, and sometimes to a considerable extent. There may be dropsy of the tunic from inflammation of the eyeball alone, but that does not concern us here. If the orbital fat exerts its fluid influence in transmitting pulsation to the eyeball, a like but still more applicable physical effect, looking at the subject comprehensively, is to be found in a bladder of fluid entirely surrounding the eyeball.

$$
\text { I am, Sir, your obedient servant, }
$$

Brook-street, W., April 5th, 1875. Haynes Walton.

\section{ \\ (4) bituxury.}

\section{THOMAS PAGET, F.R.C.S. ENG., LEICESTER.}

Tнове who live near Leicester, or who lived in Leicester fifteen or twenty years ago, will be best able to judge of the kind of sensation produced in that town and county by the announcement of Mr. Paget's death. Few men were better known by name and fame and figure. Mr. Paget had been out of active practice for some years. His connexion with the Infirmary of Leicester terminated seven or eight years ago, and he had been very effectually succeeded, both as an operator and a coneultant, by younger men, but he had been so long and withal so creditably before the public and profession of Leicester and of the Midland Counties generally, that his death occasions a sense of blank and change which is produced only by the death of men who have been exceptionally useful and conspicuous. By the public he will be long remembered as a good, clear-headed practitioner, especially in surgery. By the profession he will be remembered as an operator, whose work was characterised by coolness, precision, and success. No one in the county of Leicester twenty years ago in any surgical dilemma felt quite satisfied until he had had the benefit of the opinion of "Tom Paget," as he was often called. Mr. Paget will be remembered as one of the most successful lithotomists, to be named in the same rank with Martineau, Dalrymple, Crichton, and others. Of late years, in common, we believe, with other Leicester surgeons, he preferred the median operation in cutting for stone, to which his attention was drawn mainly by Mr. Allarton's pamphlet some twenty years ago. He had also a considerable reputation as an ophthalmic operator. His contributions to surgical literature were not numerous. He became a member of the College of Surgeons and of the Apothecaries' Hall in 1818, and an Honorary Fellow of the College in 1843. He had the great distinction of having been the first provincial surgeon elected to the Council of the College of Surgeons, though he never took an active part in its deliberations. He lived and died in the Unitarian faith, of which he was a principal supporter.

\section{HERMAN S. MAY, M.D.}

WE have to record the death of Dr. May, at his residence, No. 8, Summerlands, Exeter, on the 15th March, at the ripe age of eighty-six, after a brief illness. He was one of the oldest members of the College of Surgeons, having been admitted a member in 1810, and perhaps the oldest of the army surgeons. He was employed as assistant-surgeon at Plymouth, in 1809, to attend the wounded after the battle of Corunna, which appointment he obtained whilst a student at Guy's through the kindness of Sir Astley Cooper; but his commission in the regular army did not commence until 1810 , when he was appointed to the 81st Regiment of the Line, and joined the expedition despatched from Sicily to the East of Spain, under the command of General Lord Bentinck, to oppose the operations of Marshal Suchet's corps, then in Valencia. He was present with his regiment at the sanguinary battle of Castella, in April, 1812, and at the siege of Tarragona. Subsequently, after the battle of Waterloo, he joined the Duke of Wellington's army in Paris, and remained with the army of occupation in France until the peace.

Dr. May practised successfully at Tiverton for twenty-five years, when he retired from general practice. He then proceeded to Edinburgh with his son, who entered the hospital and schools of that city. Here they both studied together, and after the expiration of three or four years his son (since dead) took the MI D. degree of Edinburgh, while he proceeded to St. Andrews, and became M.D. of that university. He finally settled at Higher Summerlands, Exeter, where he had received his early education.

Dr. May's father and three uncles were beneficed clergymen in the north of Devon. He died without issue surviving him. After numerous legacies to his family connexions, he has bequeathed $£ 600$ to the Exeter Hospital and Eye Infirmary.

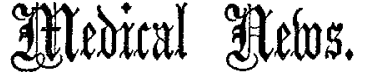

Royal College of Surgeons of England. The following gentlemen passed the primary examination in Anatomy and Physiology at meetings of the Court of Examiners on Tuesday and Wednesday last:-

W. J. Pycock, E. J. Wood, O. Tottie, and H. Lighton, Cambridge; H. J. D. Innes, G. R. Turner, and T. E. Worgan, St. George's Hocpital'; W. J. Cant, W. Leah, C. L. Williams, C. Bradord, and A. Pratt, Birmingham B. J. Newmarch, W. T. Milles, and E. Thurstan, King's College; W. S

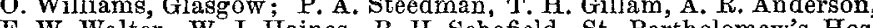

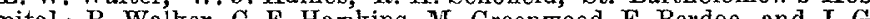
pital; R. Waker, C. F. Hawks, H. Greenwood, E. Berdoe, and J.G. Mark, London Hospital; H. Davy, A. H. Berry, J. C. Uhthoff, J. W. M. W. H. Jonce, W. Groch, W.J. C. K. Monrs, ( sex Hospital; A. Hemsted, Bellast; H. Whitehead and F. S. Boreham, Char.

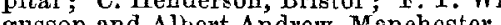

Apothecaries' Halx. - The following gentlemen passed their examination in the Science and Practice of Medicine and received certificates to practise on April 1st :Hales, Robert Turner, Holt, Norfolk. Hopking, John White, Hand ororth. Birming Maine, Walter, Francis-street, Bedford-square. Moore, Charles John, Royal Dockyard, Devonport. Sykes, John Frederick Jos., Fitzroy-square. 